\title{
Green Economy for Sustainable Development and Poverty Eradication
}

\section{Erica Novianti Lukas, M.A.}

Prasetiya Mulya Business School erica.lukas@pmbs.ac.id

\section{Doi:10.5901/mjss.2015.v6n6s5p434}

\section{Abstract}

In a green economy, growth in income and employment is driven by public and private investments that reduce carbon emissions enhance energy efficiency and lessen environmental degradation. As economic growth and investments become less dependent on liquidating environmental assets and sacrificing environmental quality, countries can attain more sustainable economic development. The Green Economy Report by UNEP's Green Economy Initiative demonstrates that the greening of economies is not a drag on growth, as in some myths about green economy. UNEP's macroeconomic model projects that a green economy would, after a few transition years, deliver more growth, reduce poverty, and generate more jobs than would a business as usual, brown economy. The methodology used in this research is cross section approach with four separate dependent variables which are GDP growth, income per capita, unemployment rate and poverty level. The key independent variable is Global Green Economy Index (GGEl) that measures performance of countries in the global green economy aspects. The observation used is obtained from secondary data which consist of 60 countries. The result shows that green economy has negative impact towards economic growth but has positive impact towards income per capita. In addition, green economy does not have a significant effect towards unemployment but it decreases the poverty level. Based on this result, both public and private sectors are recommended to continuously support and adopt green economy in the future for sustainable development and poverty eradication.

Keywords: Green Economy, Economic Growth, Sustainable Development, Unemployment, Poverty Eradication

\section{Introduction}

Climate change is one of the most powerful reminders that our economic growth has already surpassed the ecological carrying capacity of the earth. The increase in greenhouse gas emissions resulted from burning fossil fuels in the form of coal, oil and gas for electricity production is the evidence of climate change process.

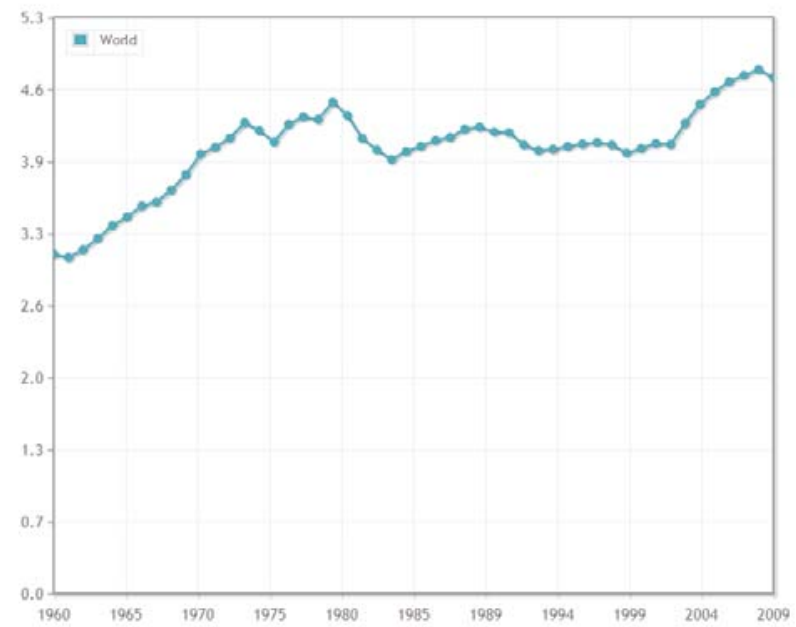

Figure 1. $\mathrm{CO}_{2}$ Emissions per capita, 1960-2009

Source: Index Mundi, World Bank, World Development Indicator - Last updated April 23, 2013 


\subsection{Green Economy}

Green economy concept has received significant international attention especially after the 2012 UN Conference on Sustainable Development (Rio+20). It is in line with continuing concerns over global economic and environmental challenges across our planet from climate change, loss of biodiversity, land degradation to rising natural resource scarcities.

United Nations Environment Programme (UNEP) defines a green economy as one that results in improved human well-being and social equity, while significantly reducing environmental risks and ecological scarcities. In its simplest expression, a green economy is low-carbon, resource efficient and socially inclusive (UNEP, 2011).

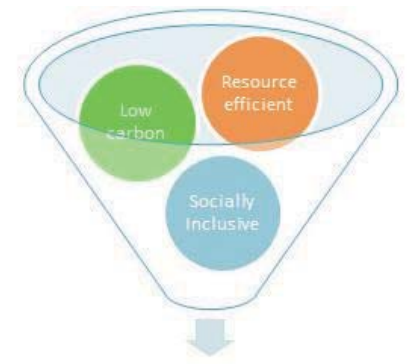

Green Economy

Figure 2. Simple Definition of Green Economy

There are some myths about green economy such as inescapable trade-off between environmental sustainability and economic progress; green economy is a luxury only wealthy countries can afford and it restrains development as well as perpetuates poverty in developing countries.

However, UNEP's report asserts that a green economy is not generally a drag on growth. UNEP's macroeconomic model projects that a green economy would, after a few transition years, deliver more growth, reduce poverty, and generate more jobs than would a business as usual, brown economy.

In a green economy, growth in income and employment is driven by public and private investments that reduce carbon emissions enhance energy efficiency and lessen environmental degradation. As economic growth and investments become less dependent on liquidating environmental assets and sacrificing environmental quality, countries can attain more sustainable economic development.

\subsection{Research Objectives}

This research is going to answer the question "Will green economy be a new engine of growth, jobs generator and poverty alleviation strategy?"

A green economy can meet challenge to economic development by offering a development path that reduces carbon dependency, promotes resource and energy efficiency and lessens environmental degradation. As economic growth and investments become less dependent on liquidating environmental assets and sacrificing environmental quality, countries can attain more sustainable economic development and become a new engine of growth.

Thus, my hypotheses are

1. Green economy has positive impact towards economic growth

2. Green economy will decrease unemployment rate and poverty level

If the impacts of green economy are significantly able to increase economic growth, decrease unemployment and alleviate poverty, this research can provide a basis of recommendation for countries and private sectors to continuously support and adopt green economy in the future.

\section{Literature Review}

There are some previous studies regarding the relationship between green economy and growth. 
- Porter's Hypothesis (Michael Porter, 1991): Well-designed environmental policies can induce efficiency and encourage innovations that can outweigh the cost of the policy.

- Environmental Policies and Productivity Growth (Tomasz Koźluk and Vera Zipperer, 2013): The study shows empirical evidence on the link between environmental policy stringency and productivity growth and the various channels through which such effects can take place. The results are ambiguous, in particular as many of the studies are fragile and context-specific, impeding the generalization of conclusions.

- Consequences of Climate Change Damages for Economic Growth (Dellink, et. al.,2014): The effect of climate change impacts on annual global GDP is projected to increase over time, leading to a global GDP loss of $0.7 \%$ to $2.5 \%$ by 2060 for the most likely equilibrium climate sensitivity range.

- Green Growth Challenge in Mexico (Carla Valdivia de Richter, 2013): Costs of environmental degradation were estimated at approximately 5\% of GDP in 2011, primarily from the health impact of air pollution, while overexploitation of natural resources - such as water - threatens their sustainability.

- Greening Growth in Luxembourg (Nicola Brandt, 2013): Strong economic growth of Luxembourg has impact towards environmental pressures. This is mainly a result of a growing population and a rapid increase in transport, which is dominated by the car.

- Does civil environmental protection force the growth of China's industrial green productivity? (Yabin Zhang, PeizhenJin, Di Feng,2015): The increase in the civil environmental protection effect promotes the industrial green technology innovation, while the rent-seeking activities have a significant negative effect on green productivity.

\subsection{Linkages between Economic Growth and Environmental Performance}

The relationship between economic growth and the environmental is controversial. Traditional economic theory views that there are generally accepted trade-off between the economic growth and environmental quality. Since the early 1990s, however, it has been suggested that the relationship between income and pollution is not linear but more like an inverted U curve or so called Environmental Kuznet Curve (EKC).

\section{Figure 3. Environmental Kuznet Curve}

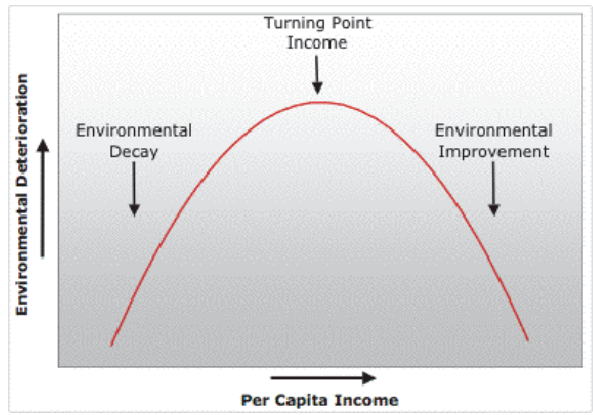

The EKC depicts that empirical pattern that at relatively low levels of income per capita, pollution initially increases as income rises, but after reaching a certain threshold, pollution decreases with rising income. Grossman and Kreuger and the World Bank made the pioneering studies which brought the EKC to public attention.

The possible explanation is that when GDP increases, the greater scale of production leads directly to more pollution, but at a higher level of income per capita, the demand for health and environmental quality rises with income which compels governments to take the necessary measures of resource allocation and regulation to improve pollution control. As a response, the private sector also adopts cleaner production methods.

\section{Methodology}

This research aims to identify the effect of green economy towards economic growth, jobs generator and poverty alleviation. In this research, a quantitative research is used by having a cross section regression with dependent variables which are GDP growth, GDP per capita, unemployment rate and poverty level. The key independent variable used in this research is Global Green Economy Index (GGEI). 


\subsection{Global Green Economy Index (GGEI)}

The Global Green Economy Index (GGEI) measures both the green economic performance of 60 countries and how experts assess that performance. Like many indices, the GGEI is a communications tool, signaling to policy makers, international organizations, the private sector and citizens which countries are successfully orienting their economies toward greener growth pathways and which ones are not.

The GGEI performance index uses quantitative and qualitative indicators to measure how well each county performs on four main dimensions: leadership \& climate change, efficiency sectors, market \& investment and environment \& natural capital. Then, the GGEI perception survey collects assessments from expert practitioners on these same four dimensions.

\section{PERFORMANCE INDEX}

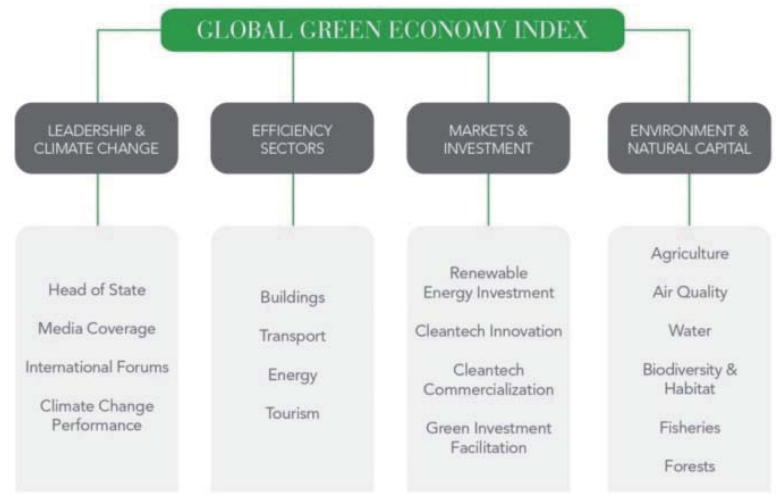

Figure 4. Main Dimensions of Global Green Economy Index

Source: 2014 Global Green Economy Index ${ }^{\mathrm{TM}}$ (GGEI), published by Dual Citizen LLC

\subsubsection{Dimension 1: Leadership \& Climate Change}

Political leadership has a critical role to play in mainstreaming the concept of green economy. A variety of leaders, particularly head of state, have powerful communications platforms to utilize, as well as policy tools that signal to the global marketplace that their country is serious in promoting green investment and industrial development.

a. Head of State: Statements and initiatives associated with head of state can serve to introduce the general public to the green economy concept, as well as signal to the market that a national economy is oriented towards green investment and economic growth.

b. Media Coverage: How countries are portrayed in global media related to the green economy suggests the extent to which their nations are communicating information and opportunities on the topic.

c. International Forums: National statements and overall behavior at international climate forums can indicate the extent to which nations are committed to green economy, sustainable development and addressing the adverse impacts of climate change in a meaningful way.

d. Climate Change Performance: The GGEI calculates three main for each nation covered: $\mathrm{CO}_{2}$ per capita, $\mathrm{CO}_{2}$ per unit of gross domestic product (GDP) and $\mathrm{CO}_{2}$ per unit of primary energy use. The resulting composite indicator provides a basic measure of where each nation performs relative to the overall GGEI coverage. It also provides the GGEI with a standard measure applicable to all 60 countries.

\subsubsection{Dimension 2: Efficiency Sectors}

The performance of efficiency sectors are at the root of the green economic prospects of most countries, especially the more developed ones. By transitioning to more efficient resource use in these sectors, many countries can realize productivity gains and lessen their greenhouse gas (GHG) emissions. 
a. Buildings: Buildings are critical to ensure more green economic growth due to their significant contribution to GHG emissions. The GGEI uses Leadership in Energy and Environmental Design (LEED) certification statistics to estimate the extent of sustainable building in the 60 countries.

b. Transport: Various forms of transportation contribute significantly to national GHG emissions. Thus, introducing efficiency to this sector is a critical step in achieving greener economic growth. The GGEI uses both the most recent emissions from the transport sector and the 10-year trend, as reported through the International Energy Agency and World Bank.

c. Energy: The GGEl uses the percentage of electricity generated from renewable sources as an estimate for the extent to which the energy sector in each country is green. The share of electricity generated by renewable power plants in total electricity generated by all types of plants data is used and gathered from International Energy Agency (IEA) and World Bank. In this instance, renewable electricity is defined as hydroelectric, geothermal, solar, tides, wind, biomass and biofuels.

d. Tourism: Sustainable tourism in the GGEI relies upon certification schemes, as well as an internal evaluation for the national tourism websites and the extent to which they communicate concrete ways for tourists to visit their country in a sustainable manner. The internal evaluation of the tourism ministry websites is based on five main factors: the extent to which sustainable tourism is featured, communication of concrete links to sustainable tourism resources in country, links to tour operators or other tourism assets who receive certification, interactive content and a social media presence to support these topics and direct links to people who can support visitors as they consider traveling to the destination.

\subsubsection{Dimension 3: Markets and Investment}

Transitioning to a green economy will require significant public and private investment to accelerate green growth.

a. Renewable Energy Investment: The GGEI uses the Renewable Energy Country Attractiveness Index (RECAI) to measure national performance in attracting renewable energy investment. Published quarterly, the frequent updating to the RECAl provides a more dynamic view of changes in each country according to three dimensions: macro drivers (i.e. macroeconomic stability, investor climate, ease of doing business); energy market drivers (i.e. prioritization of renewables, bankability of renewables); technology-specific drivers (i.e. project attractiveness).

b. Cleantech Innovation: The GGEI considers three main datasets and indicators to measure the extent to which each national market provides a vital climate for cleantech innovation. The first is each country's score on the INSEAD Global Innovation Index; the second is the number of companies located in each country listed on the Cleantech group's annual Cleantech 100 list; the third is the measure of clean energy patents issued to each country, as reported by the Clean Energy Patent Growth Index (CEPGI).

c. Cleantech Commercialization: Quantifying the extent of commercialized cleantech in each country is complicated not only by the diversity of nations covered, but also by the fact that many large, multi-national companies are heavily involved in commercializing cleantech. Thus, to estimate the extent of cleantech commercialization in the countries, the GGEI borrows results from the WWF Cleantech Group's Global Cleantech Innovation Index dealing with evidence of commercialized cleantech innovation.

d. Green Investment Facilitation: The GGEI ranks the investment promotion agency of each country it covers to determine the extent to which their efforts are oriented toward promoting and facilitating green investments. Each agency is ranked according to five main factors: the extent to which green or cleantech issues are featured in their activities; communication of national initiatives related to cleantech and green industry; data and other knowledge resources geared toward green or cleantech investors; interactive content and a social media presence to support these topics; and direct link to people who can support investors as they consider the market for future business activity.

\subsubsection{Dimension 4: Environment and Natural Capital}

There are six sub-categories defining this final dimension of the GGEl: agriculture, air quality, water, biodiversity and habitat, fisheries and forests. The GGEI derived these performance scores directly from Environmental Performance Index (EPI). The Environmental Performance Index is a joint project between the Yale Center for Environmental Law and Policy (YCELP) and the Center for International Earth Science Information Network (CIESIN) in collaboration with the World Economic Forum. 
Calculating the EPI begins with transforming raw datasets to comparable performance indicators by standardizing raw values according to population, gross domestic product or other denominators. It can also involve applying statistical transformations, such as inversions or logarithmic transformations.

EPI indicators use a "proximity-to-target" methodology, which assesses how close a particular country is to an identified policy target. That target, a high performance benchmark, is defined primarily by international or national policy goals or established scientific thresholds. Score are then converted to a scale of 0 to 100 by simple arithmetic calculation, with 0 being the farthest from the target (worst observed value) and 100 being closest to the target (best observed target).

\subsection{Dependent Variables}

\subsubsection{GDP Growth (annual \%)}

GDP growth is the annual percentage growth rate of GDP at market prices based on constant local currency. Aggregates are based on constant 2005 US Dollars. GDP is the sum of gross value added by all resident producers in the economy plus any product taxes and minus any subsidies not included in the value of the products. It is calculated without making deductions for depreciation of fabricated assets or for depletion and degradation of natural resources. The data is taken from World Development Indicators, World Bank.

\subsubsection{GDP per capita (current US\$)}

GDP per capita gross domestic product divided by midyear population. Data are in current US Dollars. The data is taken from World Development Indicators, World Bank.

\subsubsection{Total unemployment (\% of total labor force)}

Unemployment refers to the share of the labor force that is without work but available for and seeking employment. It is modeled based on ILO estimate. The data is taken from World Development Indicators, World Bank.

\subsubsection{Poverty headcount ratio at national poverty lines (\% of population)}

Data are compiled from official government sources or are computed by World Bank staff using national (i.e. countryspecific) poverty lines. The data is taken from World Development Indicators, World Bank.

\section{Results}

The cross section regression results from Stata are as follow:

\subsection{GDP growth}

reg growth ggei_perc

\begin{tabular}{rrrr} 
Source | & SS & df & MS \\
\hline Model | & 110.085554 & 1 & 110.085554 \\
Residual | & 443.215063 & 58 & 7.64163901 \\
- Total | & 553.300617 & 59 & 9.37797656
\end{tabular}

Number of obs $=60$

$\mathrm{F}(1,58)=14.41$

Prob> F $\quad 0.0004$

$\mathrm{R}$-squared $\quad=0.1990$

Adj $\mathrm{R}$-squared $=0.1852$

Root MSE $=2.7644$

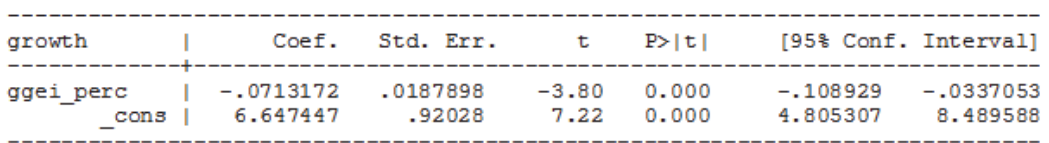

There is a statistically significant negative relationship between economic growth and environmental quality. 


\subsection{GDP per capita}

reg gdp_per_cap ggei_perc

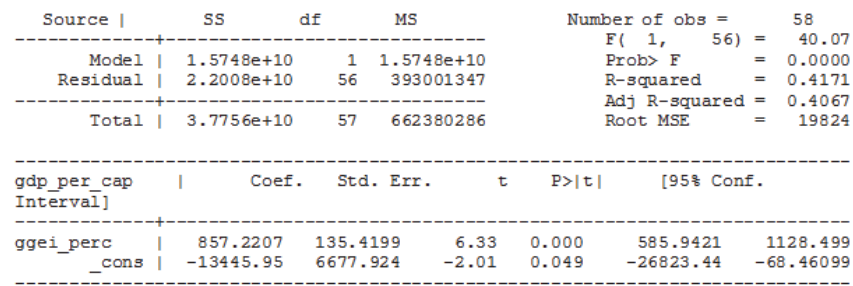

There is a statistically significant positive relationship between income per capita and environmental quality.

\subsection{Unemployment Rate}

.reg unemployment ggei_perc

\begin{tabular}{|c|c|c|c|}
\hline Source I & SS & df & MS \\
\hline Mode1 | & 3.28197501 & 1 & 3.28197501 \\
\hline Residual I & 1363.6848 & 57 & 23.9242948 \\
\hline Total & 1366.96678 & 58 & 23.5683927 \\
\hline
\end{tabular}

\begin{tabular}{ccccccr} 
unemployment | & Coef. & Std. Err. & t & P $|t|$ & [958 Conf. Interval] \\
ggei_perc & | -.0123747 & .0334109 & -0.37 & 0.712 & -.0792789 & .0545294 \\
_cons | & 7.785416 & 1.644783 & 4.73 & 0.000 & 4.491795 & 11.07904 \\
\hline
\end{tabular}

There is no statistically significant relationship between unemployment and environmental quality.

\subsection{Poverty Rate}

\begin{tabular}{|c|c|c|c|c|c|c|c|}
\hline Source I & SS & df & \multicolumn{2}{|r|}{ MS } & & $\begin{array}{l}\text { Number of obs } \\
\mathrm{F}(1,50)\end{array}$ & $\begin{array}{lr}= & 52 \\
= & 6.66\end{array}$ \\
\hline Model | & 1224.99276 & 1 & 1224 & 99276 & & & $\begin{array}{lr}= & 6.66 \\
= & 0.0128\end{array}$ \\
\hline Residual | & 9192.14655 & 50 & 183. & 842931 & & R-squared & 0.1176 \\
\hline & & & & --- & & Adj R-squared & $1=0.0999$ \\
\hline Total I & 10417.1393 & 51 & 204 & 257634 & & Root MSE & $=13.559$ \\
\hline pov_rate3 & Coef. & Std. & Err. & $t$ & $P>|t|$ & [95을 Conf. & Interval] \\
\hline ggei_perc | & -.2733085 & .105 & 5879 & -2.58 & 0.013 & -.4859727 & -.0606443 \\
\hline _cons । & 34.06853 & 4.897 & 7198 & 6.96 & 0.000 & 24.23222 & 43.90484 \\
\hline
\end{tabular}

There is a statistically significant negative relationship between poverty and environmental quality.

\subsection{Four Main Dimensions of GGEI}

\begin{tabular}{|c|c|c|c|c|c|c|c|c|c|c|}
\hline \multicolumn{3}{|c|}{ Source I } & & SS & df & & MS & & \multirow{2}{*}{$\begin{array}{l}\text { Number of obs } \\
\text { F( 4, 55) }\end{array}$} & \multirow{2}{*}{$\begin{array}{lr}= & 60 \\
= & 13.01 \\
= & 0.0000\end{array}$} \\
\hline \multirow{2}{*}{\multicolumn{3}{|c|}{$\begin{array}{r}\text { Model | } \\
\text { Residual | }\end{array}$}} & \multicolumn{2}{|c|}{268.989774} & 4 & \multicolumn{2}{|c|}{67.2474435} & & & \\
\hline & & & 284 & 310843 & 55 & 5.1 & 6928806 & & R-squared & $=0.4862$ \\
\hline \multicolumn{3}{|c|}{ Total I } & 553 & 300617 & 59 & 9.3 & 7797656 & & Root MSE & $\begin{array}{l}= \\
=\quad .4480 \\
\end{array}$ \\
\hline growth & 1 & & sef. & Std. Err. & & $\mathrm{t}$ & $p>|t|$ & [958 Conf. & Interval] & \\
\hline perf_lc & 1 & .126 & 1959 & .2096643 & & .60 & 0.550 & -.2939808 & .5463725 & \\
\hline perf_es & 1 & .058 & 8885 & .2600418 & & .23 & 0.822 & -.4622468 & .5800239 & \\
\hline perf_mi & 1 & -.883 & 1338 & .1806439 & -4 & .89 & 0.000 & -1.245152 & -.5211154 & \\
\hline perf_en & i & -.517 & 9047 & .2441709 & & .12 & 0.038 & -1.007234 & -.0285753 & \\
\hline _cons & i & 9.27 & 6551 & 1.69593 & & .47 & 0.000 & 5.877831 & 12.67527 & \\
\hline
\end{tabular}


Among the four main dimensions of Global Green Economy Index (GGEI), market \& investment and environmental \& natural capital are the ones who have statistically significant negative effect toward economic growth.

. reg gdp_per_cap perf_lc perf_es perf_mi perf_en

\begin{tabular}{|c|c|c|c|c|c|c|c|c|c|c|}
\hline \multicolumn{3}{|c|}{ Source } & & sS & df & & MS & & $\begin{array}{l}\text { Number of obs } \\
F(4, \quad 53)\end{array}$ & \multirow{2}{*}{$\begin{array}{r}58 \\
9.48 \\
0.0000\end{array}$} \\
\hline \multirow{2}{*}{\multicolumn{3}{|c|}{$\begin{array}{r}\text { Model } \\
\text { Residual }\end{array}$}} & \multicolumn{2}{|c|}{$1.5745 \mathrm{e}+10$} & 4 & \multicolumn{2}{|c|}{$3.9362 \mathrm{e}+09$} & & Prob> F & \\
\hline & & & 2.2 & $11 e+10$ & 53 & & 299402 & & R-squared & $=0.4170$ \\
\hline \multirow{2}{*}{\multicolumn{3}{|c|}{ Total }} & & & & & 380286 & & \multirow{2}{*}{$\begin{array}{l}\text { Adj R-squared } \\
\text { Root MSE }\end{array}$} & 0.3730 \\
\hline & & & 3.7 & $56 e+10$ & 57 & & 380286 & & & 20379 \\
\hline gdp_per_c & cap & 1 & oef. & Std. Err. & & t & $p>|t|$ & [958 Conf. & Interval] & \\
\hline perf_lc & 1 & -217 & .044 & 1895.919 & -1.1 & 15 & 0.257 & -5973.776 & 1631.687 & \\
\hline perf_es & 1 & & 3.28 & 2336.418 & & 15 & 0.254 & -1992.981 & 7379.541 & \\
\hline perf_mi & 1 & 479 & 929 & 1643.96 & 2.9 & 91 & 0.005 & 1493.563 & 8088.295 & \\
\hline perf_en & 1 & 520 & .068 & 2226.591 & 2.3 & 34 & 0.023 & 737.0934 & 9669.043 & \\
\hline _cons & 1 & -243 & 0.01 & 15426.19 & -1.5 & 58 & 0.121 & -55251.03 & 6631.016 & \\
\hline
\end{tabular}

Among the four main dimensions of Global Green Economy Index (GGEI), market \& investment and environmental \& natural capital are the ones who have statistically significant positive effects toward income per capita.

reg unemployment perf_c perf_es perf_mi perf_en

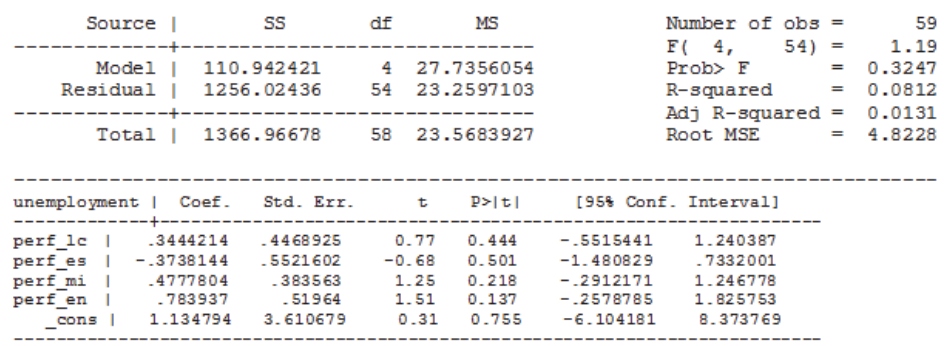

Among the four main dimensions of Global Green Economy Index (GGEI), there is no single aspect that has a statistically significant effect toward unemployment.

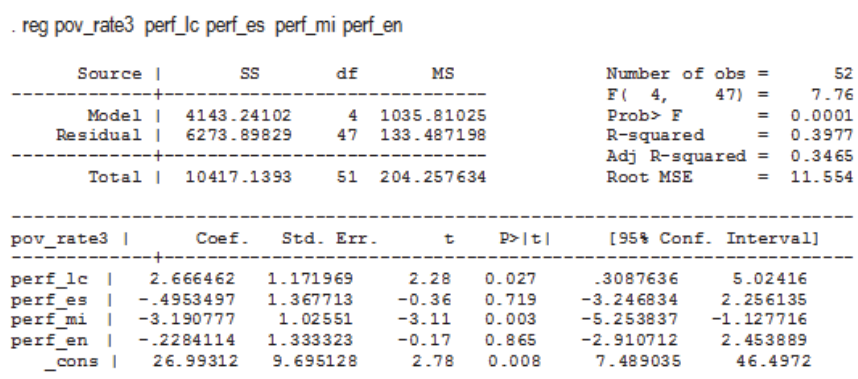

Among the four main dimensions of Global Green Economy Index (GGEI), leadership \& climate change has a statistically significant positive effect toward poverty, meanwhile market \& investment has a statistically significant negative effect toward poverty.

\section{Discussion and Analysis}

The findings indicate that the green economy has negative relationship with economic growth; however it has positive impact toward income per capita. It makes sense because the countries that have good ranks in GGEl are mostly developed countries. The characteristic of developed countries are usually they have low GDP growth and high GDP per capita. 
For further research, to gain more accurate insight about the impacts, we can differentiate between the developed countries and developing countries to see how green economy affects economic growth and income per capita. By doing so, we can also prove whether the Environmental Kuznets Curve is applied or not.

Among the four main dimensions of Global Green Economy Index (GGEI), market \& investment and environmental \& natural capital are the ones who have statistically significant negative effects toward economic growth and positive effects toward income per capita. Market and investment dimension consists of both public and private investment to accelerate growth such as renewable energy investment, cleantech innovation, cleantech commercialization and green investment facilitation. These green investments will boost the economy of the country as well as the income per capita.

The other important dimension of the green economy that has significant impact to economic growth and income per capita is environmental and natural capital. It is logical that countries which have high quality of natural resources in the form of agriculture, air quality, water, biodiversity, fisheries and forests will have a greater level of economy. This is because in the production function, one of the input factors is natural resource. Thus, with a greater environment and natural capital will lead to greater economy.

The hypothesis regarding unemployment is not proved because based on the result there is no significant impact of green economy as well as all of its dimensions toward unemployment. Green economy does not increase the employment directly because the effect to employment is indirect through economic output. When output rises, the employment will increase, unemployment will decrease. However, this indirect effect is relatively small and does not affected by green economy significantly. Perhaps, if we only consider developing countries, the effect may be more significant.

In general, green economy decreases the poverty rate in each country based on their national standard. It means that by having a greater environmental quality, the particular country has a lower poverty level. Among the main dimensions of the GGEI, there are two dimensions that are significant affecting the poverty. Market and investment has a negative effect toward poverty because the advancement of green investment will increase the GDP per capita as well as the living standard of the people in the country. By having a rising economic standard of life, people that have income less than poverty line for each country will decrease. On the other hand, leadership and climate change has a positive effect toward poverty but it is smaller than the effect from market and investment dimension.

The methodology used in this paper still can be improved for further research. One potential problem that might arise in the cross section regression is endogeneity which is caused by a loop of causality between the independent and dependent variables in the model. To overcome that problem, the possible solution is by adding lags or having some instrumental variables.

\section{Conclusion}

The results show that green economy has negative impact towards economic growth but has positive impact towards income per capita. The main dimensions of GGEI that significantly affecting the economy output are market and investment as well as environment and natural capital. In addition, green economy does not have a significant effect towards unemployment but it decrease poverty level.

This research provide temporary conclusion for us based on the result. As economic growth and investments become less dependent on liquidating environmental assets and sacrificing environmental quality, countries can attain more sustainable economic development. Both public and private sectors are recommended to continuously support and adopt green economy in the future for sustainability and poverty eradication. For further research, the methodology can be improved by differentiating developing and developed countries as well as adding an instrumental variable to overcome the endogeneity issue to get the more accurate results.

\section{References}

Albrizio, Silvia,Enrico Botta, Tomasz Koźluk, Vera Zipperer. (2014). Do Environmental Policies Matter for Productivity Growth?: Insights from New Cross-Country Measures of Environmental Policies. OECD Economics Department Working Papers 1176, OECD Publising.

Brandt, Nicola. (2013) Greening Growth in Luxembourg. OECD Economics Department Working Papers 1063, OECD Publising.

Dellink, Rob, Elisa Lanzi, Jean Chateau, Francesco Bosello, Ramiro Parrado, Kelly de Bruin. (2004). Consequences of Climate Change Damages for Economic Growth: A Dynamic Quantitative Assesment. OECD Economics Department Working Papers.

De Ritcher, Carla Valdivia. Green Growth Challenges and the Need for An Energy Reform in Mexico. OECD Economics Department Working Papers 1095, OECD Publising.

Porter, Michael E. and Claas van der Linde. (1995). Toward a New Conception of the Environment-Competitiveness Relationship. 
Journal of Economic Perspectives, Vol. 9, No. 4, 97-118.

UNEP. (2011). Towards a Green Economy: Pathways to Sustainable Development and Poverty Eradication. www.unep.org/greeneconomy

Zhang, Yabin, PeizhenJin, Di Feng. (2015). Does Civil Environmental Protection Force the Growth of China's Industrial Green Productivity?. Ecological Indicators Vol. 51 Environmental Issues in China: Monitoring, Assessment and Management.

http://www.data.worldbank.org

http:// www.dualcitizeninc.com/global-green-economy-index/ 